\title{
Hypofractionated vs. standard radiotherapy for locally advanced limited-stage small cell lung cancer
}

\author{
Nadia A. Saeed ${ }^{1}$, Lan Jin ${ }^{2}$, Alexander W. Sasse ${ }^{1}$, Arya Amini ${ }^{3}$, Vivek Verma ${ }^{4}$, Nataniel H. Lester-Coll ${ }^{5}$, \\ Po-Han Chen ${ }^{6}$, Roy H. Decker ${ }^{1}$, Henry S. Park ${ }^{1}$ \\ ${ }^{1}$ Department of Therapeutic Radiology, Yale School of Medicine, New Haven, CT, USA; ${ }^{2}$ Department of Surgery, Yale School of Medicine, New \\ Haven, CT, USA; ${ }^{3}$ Department of Radiation Oncology, City of Hope, Duarte, CA, USA; ${ }^{4}$ Department of Radiation Oncology, University of \\ Texas M.D. Anderson Cancer Center, Houston, TX, USA; ${ }^{5}$ Division of Radiation Oncology, University of Vermont Larner College of Medicine, \\ Burlington, VT, USA; ${ }^{2}$ Department of Pathology, Yale School of Medicine, New Haven, CT, USA \\ Contributions: (I) Conception and design: All authors; (II) Administrative support: HS Park; (III) Provision of study materials or patients: HS Park; (IV) \\ Collection and assembly of data: HS Park; (V) Data analysis and interpretation: NA Saeed, L Jin, AW Sasse, HS Park; (VI) Manuscript writing: All \\ authors; (VII) Final approval of manuscript: All authors. \\ Correspondence to: Henry S. Park, MD, MPH. Assistant Professor of Therapeutic Radiology, Yale School of Medicine, 35 Park Street, Lower Level \\ 513, New Haven, CT 06511, USA. Email: henry.park@yale.edu.
}

Background: Hypofractionated radiotherapy in locally advanced limited-stage small cell lung cancer is preferred in many Western countries but not used regularly in the United States. We examined practice patterns and overall survival with definitive hypofractionated radiotherapy and chemotherapy $v s$. standard radiotherapy in this setting.

Methods: We included patients in the National Cancer Database with unresected primary stage II-III small cell lung cancer in 2008-2016 who underwent chemotherapy within six months of either hypofractionated radiotherapy (40-45 Gy/15 fractions) or standard radiotherapy (45 Gy/30 fractions or 60-70 Gy /30-35 fractions) in this retrospective cohort study. Patient characteristics were assessed with univariable and multivariable logistic regression. Kaplan-Meier estimator, log-rank test, and multivariable Cox regression were used to evaluate overall survival. Propensity score matching (PSM) was performed as a sensitivity analysis. Early concurrent chemotherapy consisted of radiotherapy and chemotherapy initiated within 30 days of each other.

Results: Seven thousand and one hundred forty-three patients were included: $97.9 \%$ received standard radiotherapy and $2.1 \%$ hypofractionated radiotherapy. Multivariable analysis on the whole cohort yielded comparable overall survival (HR for hypofractionated radiotherapy 1.09, CI: 0.90-1.32, P=0.37). On PSM ( $\mathrm{N}=292)$, median overall survival was similar between standard radiotherapy [22.9 months (95\% CI: 18.230.4 months)] vs. hypofractionated radiotherapy [21.2 months (CI: 16.3-24.7 months); $\mathrm{P}=0.13$ ]. Overall survival was shorter with hypofractionated radiotherapy in the early concurrent chemotherapy subset (15.8 vs. 22.1 months, $\mathrm{P}=0.007$ ) and longer with hypofractionated radiotherapy in the non-early concurrent chemotherapy subset (29.5 vs. 18.5 months, $\mathrm{P}=0.027)$.

Conclusions: Overall survival with hypofractionated radiotherapy appears similar to standard radiotherapy in locally advanced limited-stage small cell lung cancer. Chemotherapy timing may modify the effect of fractionation on overall survival, though larger numbers must confirm. Hypofractionated radiotherapy may be considered in those unable to receive early concurrent chemotherapy.

Keywords: Radiation dose hypofractionation; small cell lung carcinoma; chemoradiotherapy; concurrent chemoradiation; combined modality therapy

Submitted Sep 29, 2021. Accepted for publication Jan 11, 2022.

doi: $10.21037 /$ jtd-21-1566

View this article at: https://dx.doi.org/10.21037/jtd-21-1566

(c) Journal of Thoracic Disease. All rights reserved. 


\section{Introduction}

Current management of inoperable locally advanced limited-stage small cell lung cancer (LS-SCLC) may include standard radiation therapy (RT) consisting of highdose conventionally fractionated RT (CFRT) or accelerated RT in addition to chemotherapy (1). Early concurrent chemoradiation (RT initiated with the first or second cycle of chemotherapy) has been associated with superior outcomes in this setting (2). Several fractionation schedules for locally advanced LS-SCLC have been explored. Among these, accelerated RT with 45 Gy in 30 twice-daily fractions of 1.5 Gy remains the standard of care in the United States following the Turrisi trial, although overall survival (OS) is similar to 66 Gy in 33 fractions in the CONVERT trial and to 70 Gy in 35 fractions in the Radiation Therapy Oncology Group (RTOG) 0538/Cancer and Leukemia Group B (CALGB) 30610 trial (3-5).

There has been increasing interest in hypofractionated RT (HFRT) in locally advanced LS-SCLC, particularly during the Coronavirus Disease 2019 (COVID-19) pandemic to minimize exposure and resource utilization (6). Additionally, HFRT is likely more convenient for patients and less expensive than standard RT. Although there is some limited data in the United States for HFRT with 45-60 Gy in 15 fractions for non-small cell lung cancer (NSCLC), HFRT for locally advanced LS-SCLC has not yet been used with regularity in the United States $(7,8)$. In contrast, HFRT is frequently used in other Western countries and is the most common regimen in Canada and the United Kingdom (9). While there is no precise definition for HFRT, HFRT in stage II-III SCLC most often consist of 40-45 Gy in 15 fractions (9). Importantly, HFRT with this regimen has been shown to result in similar median progression-free survival (PFS) and similar toxicity compared to accelerated RT in a randomized phase II trial in LS-SCLC, although HFRT was associated with a nonsignificant decrease in OS (10).

Additionally, some smaller institutional studies have found comparable or occasionally improved locoregional control and/or survival without significantly increased toxicity with HFRT compared to standard RT in this setting (11-19). However, the data in this setting is limited, particularly in US populations. Given the logistic and possibly economic benefits of HFRT as well as the promising results from limited existing data, we conducted a large national database analysis to determine whether HFRT with 40-45 Gy in 15 fractions is being applied differently among various subpopulations and is associated with similar OS compared to standard RT in this setting. We also aimed to elucidate whether the timing of chemotherapy modifies the effect of fractionation schedule on OS among patients in this setting. We present the following article in accordance with the STROBE reporting checklist (available at https://jtd. amegroups.com/article/view/10.21037/jtd-21-1566/rc).

\section{Methods}

\section{Patient selection}

A total of 7,143 patients identified from the National Cancer Database (NCDB), which contains hospital registry data from more than 1,500 Commission on Canceraccredited facilities, were included in this retrospective cohort study (20). Jointly maintained by the American Cancer Society and American College of Surgeons, this clinical oncology outcomes database captures more than $70 \%$ of newly diagnosed cases in the United States (21). All patients were diagnosed between 2008-2016 with primary locally advanced LS-SCLC (stage II-III) according to the American Joint Committee on Cancer (AJCC)/Union for International Cancer Control (UICC) staging guidelines based on year of diagnosis $\left(6^{\text {th }}\right.$ edition for patients diagnosed in 2008-2009, and $7^{\text {th }}$ edition for patients diagnosed in 2010-2016). Patients with stage I disease were excluded due to radiotherapy treatment primarily with stereotactic body radiotherapy, which is beyond the scope of this study. The NCDB does not contain variables to indicate positron emission tomography (PET) staging, magnetic resonance imaging (MRI) brain staging, or invasive mediastinal staging. We used the NCDB variables for clinically determined T stage, $\mathrm{N}$ stage, $\mathrm{M}$ stage, overall TNM stage, and site-specific metastasis to select for patients with stage II-III disease. All patients underwent external beam RT (either standard RT or HFRT) and received chemotherapy initiated within six months of the start of RT. Patients who received surgery were excluded as were those with unknown vital status. Figure 1 shows complete exclusion criteria. This study was conducted in accordance with the Declaration of Helsinki (as revised in 2013). As all patient information was de-identified, this study was exempt from institutional review board approval (Yale) and informed consent.

\section{Variable definitions}

Standard RT was defined as either 45 Gy in 30 fractions 


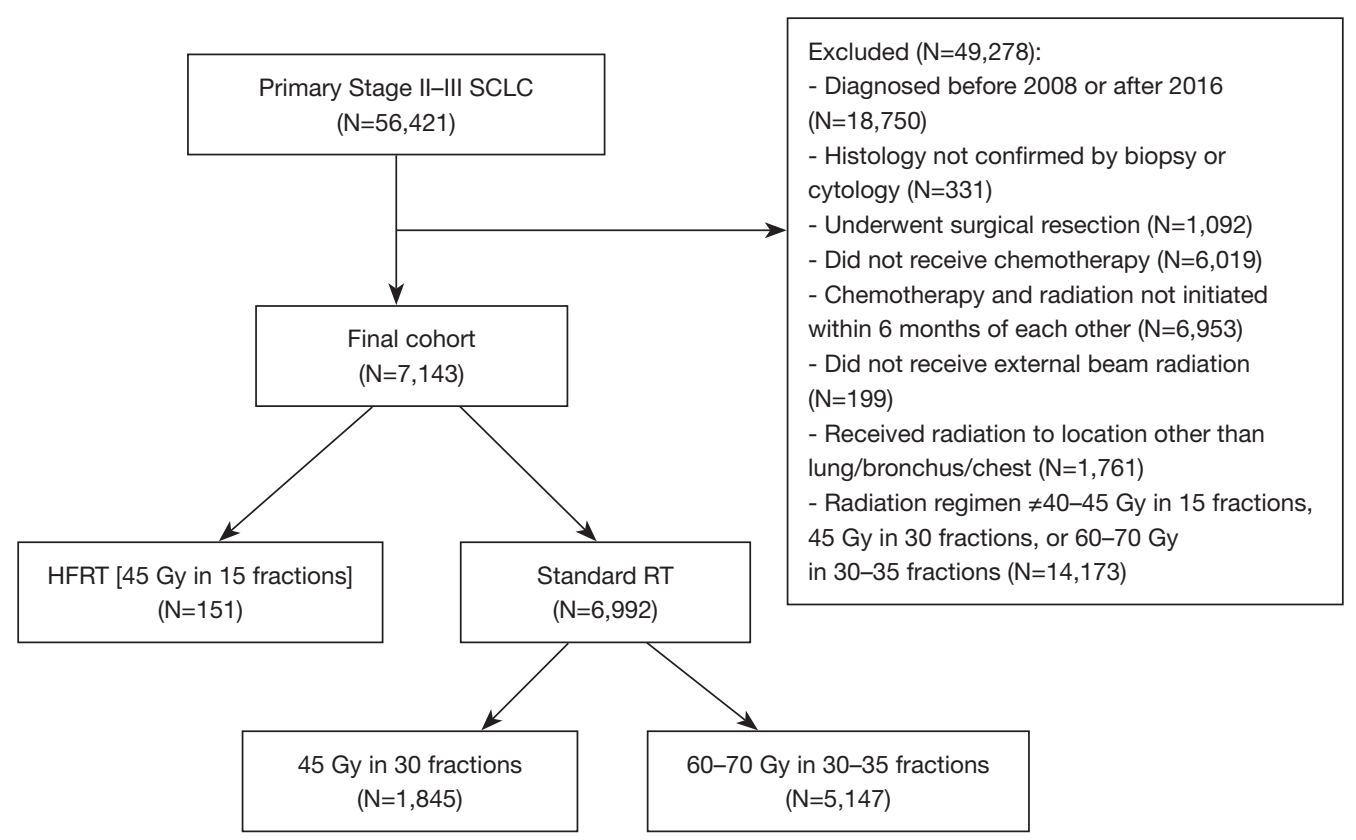

Figure 1 Exclusion criteria used in creating patient cohort.

(the standard of care per the Turrisi trial) 60-70 Gy in 30-35 fractions (to capture both 66 Gy in 33 fractions per the CONVERT trial and $70 \mathrm{~Gy}$ in 35 fractions per the RTOG 0538/CALGB 30610 trial) (3-5). HFRT was defined as 40-45 Gy in 15 fractions, as this represents one of the most commonly utilized hypofractionated schedules in Western countries (9). Chemotherapy was characterized as either early concurrent (RT and chemotherapy initiated within 30 days of each other) or as non-early concurrent (RT and chemotherapy initiated greater than 30 days apart), given the National Comprehensive Cancer Network (NCCN) recommendation for RT to be started "early" with the first or second cycle of systemic therapy (2).

Greater circle distance (proximity of patient residence to reporting facility based on patient and facility zip codes) was categorized into less than or equal to ten miles (the median in our cohort), greater than ten miles, or unknown. The NCDB estimates median household income by area of residence; we categorized by the median for this variable based on the year of diagnosis. For the ruralurban continuum variable, NCDB classifies metropolitan areas by population size and urban/rural areas by degree of urbanization and proximity to metro counties. We categorized this variable as metropolitan counties with a population of 250,000 or more, other areas (including metropolitan counties with a population of less than
250,000 , urban counties, or rural counties), or not available. Data on Medicaid expansion state status, facility type, and facility location were suppressed for patients aged 0-39 in the NCDB. Medicaid expansion state status was classified into expansion states \{including early [2010-2013], January 2014, and late (after January 2014) expansion states\}, non-expansion states, or suppressed. Regarding facility characteristics, academic facilities included National Cancer Institute (NCI) designated comprehensive cancer centers while non-academic facilities included Community Cancer, Comprehensive Community Cancer, and Integrated Network Cancer Programs.

\section{Statistical analysis}

Chi-square, Fisher's exact test, and analysis of variance (ANOVA) were used in performing univariable analysis (UVA) to evaluate sociodemographic and clinicopathologic variables associated with receipt of HFRT. Variables with $\mathrm{P}<0.2$ on chi-square analysis were included in multivariable logistic regression analysis (multivariable analysis $=\mathrm{MVA}$ ), which was performed using manual backwards stepwise selection with a $\mathrm{P}$ value threshold of 0.2. Goodness-offit testing was used to evaluate the multivariable logistic regression models.

Propensity score matching (PSM) analysis was 
performed as a sensitivity analysis to reduce the effect of possible known confounders on OS outcomes. Potential confounders were selected $a$ priori based on clinical judgement rather than statistical significance (22). These variables, which were used in the logistic regression model to estimate propensity scores, included age, race/ethnicity, presence of comorbidities, timing of chemotherapy receipt (for the PSM analysis involving the whole cohort), overall TNM stage, and facility type. Patients with unknown values for any of these covariates were excluded prior to estimating the propensity scores. We used propensity scores to perform 1-to-1 nearest neighbor matching without replacement using a caliper distance of $20 \%$ of the standard deviation of the logit of the propensity score (23). Balance of distribution for each of the covariates included in the propensity score logistic regression model was assessed with standardized percentage bias between the treated and control groups in the matched cohort; a standardized bias of less than $5 \%$ was considered to be acceptable balance on the covariate (24).

We performed survival analysis in both our original, non-matched cohort as well as our PSM cohort. OS was calculated with the Kaplan-Meier estimator. Survival differences were compared with the log-rank test for non-matched patients and the stratified log-rank test for matched patients (22). For non-matched (all) patients, we used both univariable Cox regression and multivariable Cox regression including those variables that were used in the PSM as covariates. Additionally, two interaction terms were included in the original multivariable Cox models for non-matched patients: one for the interaction between fractionation and timing of chemotherapy, and a separate one for the interaction between fractionation and TNM stage. We used univariable Cox proportional hazard $(\mathrm{PH})$ regression stratified by matched pairs to assess the impact of fractionation on OS in our PSM cohorts $(25,26)$; multivariable Cox regression was additionally performed for matched pairs if any of the covariates used in matching had a standardized bias $>5 \%$ after PSM in order to adjust for residual confounding using a doubly robust approach (27). Potential violations of the $\mathrm{PH}$ assumption were tested using Schoenfeld residuals. Covariates that did not meet $\mathrm{PH}$ assumption were stratified on; interaction terms that violated the $\mathrm{PH}$ assumption were removed from the model. Statistical significance for all analyses was defined as $\mathrm{P} \leq 0.05$. Stata/SE 15.1 software was used to perform all statistical analyses.

Subset analysis was performed to assess whether the timing of chemotherapy influenced the effect of RT fractionation schedule on survival outcomes. The analyses mentioned above were performed in the subset of patients who received early concurrent chemotherapy, as well as separately in the subset of patients who received non-early concurrent chemotherapy. We also performed sensitivity analysis using a cutoff of 60 days rather than 30 days between the start of RT and the start of chemotherapy to distinguish early concurrent chemotherapy from non-early concurrent chemotherapy.

\section{Results}

\section{Patient characteristics}

The median age in our entire cohort was 64 years [interquartile range (IQR), 57-71 years], and a majority of patients were female $(\mathrm{N}=4,023 ; 56.3 \%)$. Of the 7,143 patients with primary locally advanced LS-SCLC included in our study, 6,992 (97.9\%) underwent standard RT and 151 (2.1\%) underwent HFRT. Among those who underwent standard RT, 1,845 (25.8\%) received 45 Gy in 30 fractions, and 5,147 (72.1\%) received 60-70 Gy in $30-35$ fractions; 758 (10.6\%) patients in our non-matched cohort received 66 Gy in 33 fractions, and 276 (3.9\%) patients received $70 \mathrm{~Gy}$ in 35 fractions. The median number of days from diagnosis to the start of RT and from diagnosis to the start of chemotherapy were 42 days (IQR, 28-64) and 22 days (IQR, 13-35) for those who received standard RT and 63 days (IQR, 38-131) and 21 days (IQR, 13-34) for those who received HFRT, respectively. The majority of patients in our cohort underwent early concurrent chemotherapy $(\mathrm{N}=5,137 ; 71.9 \%)$. The proportion of patients who underwent early concurrent chemotherapy was significantly increased in the standard RT group compared to HFRT group ( $72.4 \%$ vs. $47.7 \%, \mathrm{P}<0.001)$. Most patients had stage III disease ( $\mathrm{N}=6,089 ; 85.2 \%)$. Data on tumor location beyond laterality was unavailable for our cohort in the database. Table S1 shows patient, pathologic, and treatment characteristics for all patients. All supplementary materials can be found in the supplementary appendix online.

\section{Factors associated with receipt of hypofractionated $R T$}

On MVA including the entire cohort, factors statistically significantly associated with receipt of HFRT compared to standard RT included belonging to a Medicaid expansion state [odds ratio (OR) 2.24, confidence interval (CI): $1.49-3.37, \mathrm{P}<0.001]$, living in a metropolitan area with 

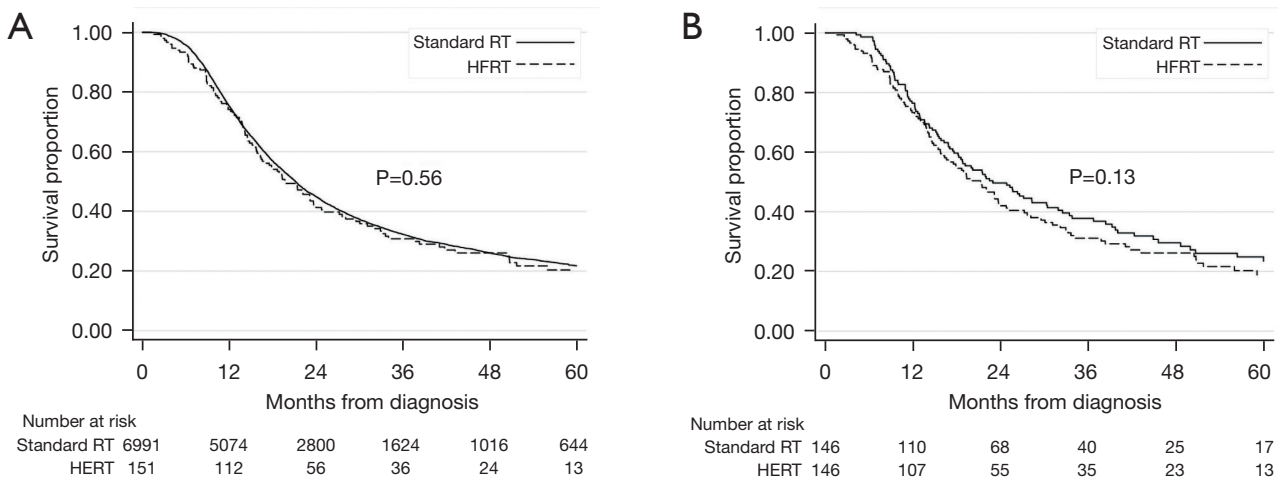

Figure 2 Overall survival comparison with 60 months follow-up by type of radiation received. (A) Overall survival comparison between standard radiation (standard RT) vs. hypofractionated radiation therapy (HFRT) among the whole cohort (N=7,143). (B) Overall survival comparison between standard radiation (standard RT) vs. hypofractionated radiation therapy (HFRT) among the propensity score matched cohort $(\mathrm{N}=292)$.

250,000+ residents (OR 1.61, CI: 1.05-2.44, $\mathrm{P}=0.027$ ), receipt of non-early concurrent chemotherapy (OR 3.05, CI: 2.19-4.24, $\mathrm{P}<0.001$ ), N1 (OR 2.70, CI: 1.14-6.35, $\mathrm{P}=0.023)$ or $\mathrm{N} 3$ (OR 2.51, CI: $1.10-5.72, \mathrm{P}=0.029)$ nodal status, treatment at an academic facility (OR 3.85, CI: 2.70-5.56, $\mathrm{P}<0.001)$, and treatment at a non-East coast facility (OR 1.80, CI: 1.26-2.56, $\mathrm{P}=0.001$ ) (Table S2). Among the subset of patients who received early concurrent chemotherapy, HFRT was significantly associated with male sex, belonging to a Medicaid expansion state, living in a metropolitan area with $250,000+$ population, N3 nodal status, treatment at an academic facility, and treatment at a non-East Coast facility on MVA. On MVA in the group of patients who received non-early concurrent chemotherapy, Medicaid expansion state status and treatment at an academic facility were significantly associated with receipt of HFRT. Characteristics of patients receiving HFRT $v s$. standard RT in the early concurrent chemotherapy and non-early concurrent chemotherapy subsets are provided in Tables S3,S4, respectively.

\section{Survival outcomes in all patients and matched cobort}

Among the entire cohort $(\mathrm{N}=7,143)$, median follow-up times for those who received standard RT and HFRT were 52.7 (CI: 51.2-54.5) and 55.9 (CI: 43.9-71.6) months, respectively. There was no significant difference in median OS between those who received standard RT $v$ s. HFRT on either UVA [21.2 months (CI: 20.6-21.6) vs. 19.8 months (CI: 16.3-23.7), log-rank $\mathrm{P}=0.56$; HR 1.06, CI: $0.88-1.27$, $\mathrm{P}=0.56]$ or MVA (HR 1.09, CI: $0.90-1.32, \mathrm{P}=0.37$ ) in all patients. On MVA, comorbidity score, TNM stage, and the interaction between fractionation schedule and chemotherapy timing violated the $\mathrm{PH}$ assumption; both interaction terms were removed from the final MVA model, which was stratified by comorbidity score and TNM stage.

On sensitivity analysis involving the PSM cohort ( $\mathrm{N}=292)$, median follow-up time for patients who received standard RT was 59.7 months (CI: 43.1-77.0 months) compared to 56.6 months (CI: 43.9-71.6 months) in patients who received HFRT. There was no significant difference in OS based on fractionation schedule in this matched cohort. Median OS was 22.9 months (CI: 18.2-30.4 months) in patients who received standard RT vs. 21.2 months (CI: 16.3-24.7 months) in those who received HFRT (stratified log-rank $\mathrm{P}=0.13$ ). Univariable Cox regression stratified by matched pairs yielded a HR of 1.30 (CI: $0.92-1.85)$, although this was non-significant $(\mathrm{P}=0.14)$. Multivariable Cox regression was additionally performed for this matched cohort including the covariates age and race/ ethnicity (as both these variables had residual standardized bias $>5 \%$ after matching), which yielded a HR 1.35 (CI: 0.94-1.93, $\mathrm{P}=0.10$ ). Figure $2 A, 2 B$ and Table 1 display survival data for the whole cohort and PSM cohort, respectively.

\section{Survival outcomes in early concurrent and non-early concurrent chemotherapy subsets}

Among the non-matched subset of patients who received early concurrent chemotherapy $(\mathrm{N}=5,137)$, OS was also longer in those who underwent standard RT $(\mathrm{N}=5,065)$ compared to HFRT (N=72). This difference was statistically 
Table 1 Univariable and multivariable Cox regression analysis for variables potentially associated with overall survival in non-matched (all) patients $(\mathrm{N}=7,143)$ and matched patients $(\mathrm{N}=292)$

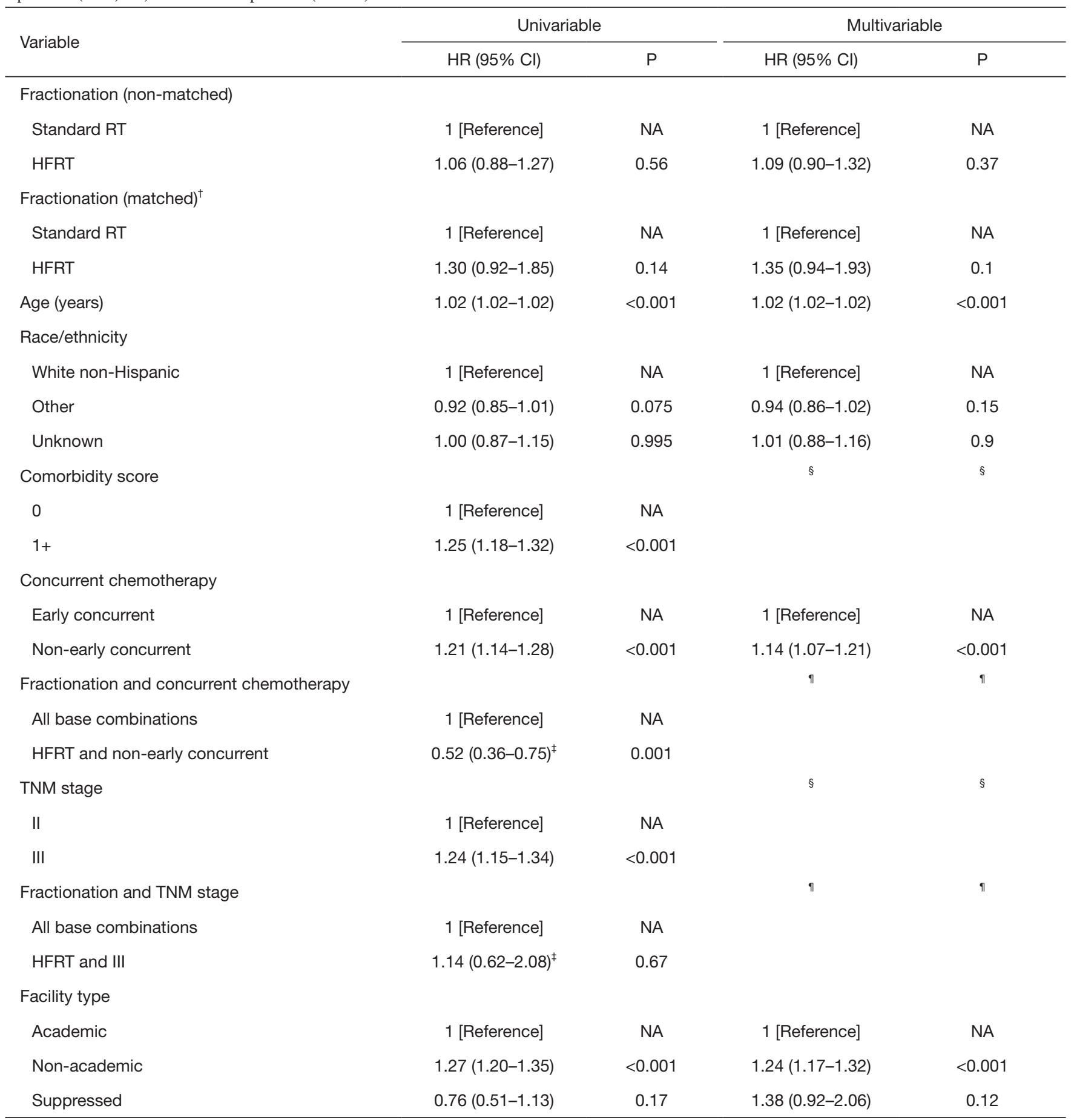

${ }^{\dagger}$, Cox regression stratified by matched pairs; ${ }^{\ddagger}, \mathrm{HR}$ indicates OS associated with the interaction term in a model containing the interaction term and both variables that form the term; ${ }^{\S}$, final MVA model stratified by comorbidity score and TNM stage; ", interaction terms not included in final MVA model. HR, hazard ratio; Cl, confidence interval; RT, radiation therapy; HFRT, hypofractionated radiation therapy. 

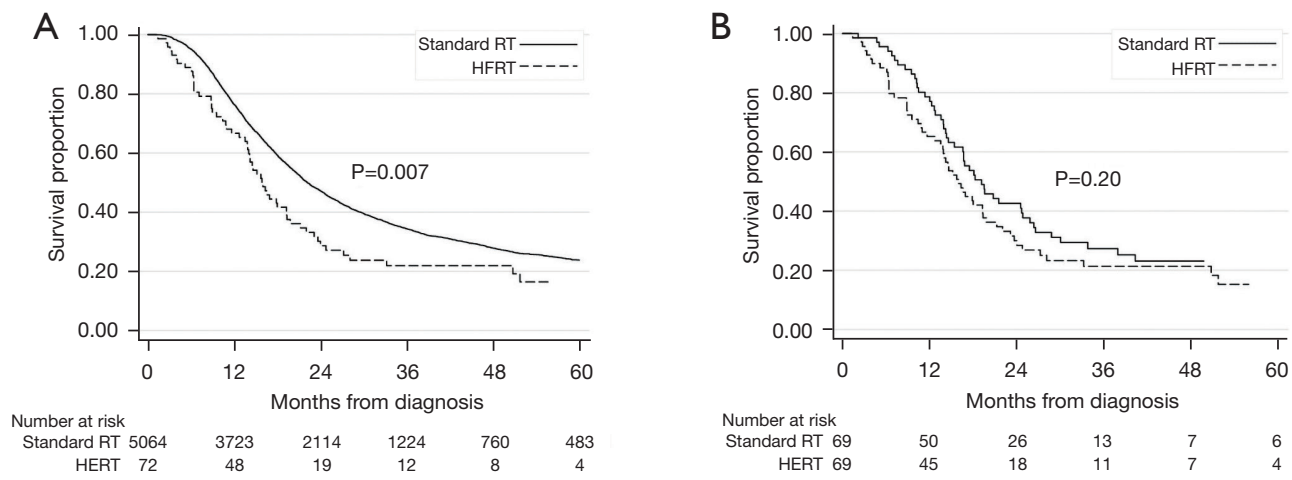

Figure 3 Overall survival comparison with 60 months follow-up by type of radiation received among patients who underwent early concurrent chemotherapy. (A) Overall survival comparison between standard radiation (standard RT) vs. hypofractionated radiation therapy (HFRT) among the non-matched subset of patients who received early concurrent chemotherapy (N=5,137). (B) Overall survival comparison between standard radiation (standard RT) vs. hypofractionated radiation therapy (HFRT) among the propensity score matched subset of patients who received early concurrent chemotherapy $(\mathrm{N}=138)$.

significant on both UVA [22.1 months (CI: 21.5-23.0) vs. 15.8 months (CI: 13.9-19.3), log-rank $\mathrm{P}=0.007$; HR 1.44, CI: $1.10-1.86, \mathrm{P}=0.007]$ and MVA (HR 1.50, CI: 1.16-1.96, $\mathrm{P}=0.002)$. Median follow-up times for those who received standard RT and those who received HFRT among all patients in the early concurrent chemotherapy subset were 51.2 (CI: 49.2-52.8) and 53.3 (CI: 37.1-71.2) months, respectively. Among the matched subset of patients who received early concurrent chemotherapy $(\mathrm{N}=138)$, OS was numerically longer in those who received standard RT compared to HFRT [19.1 (CI: 15.4-24.8) vs. 16.0 (CI: 13.519.3) months], although this difference was not statically significant (stratified log-rank $\mathrm{P}=0.20$ ). Univariable Cox regression yielded a HR of 1.4 (CI: 0.84-2.34, $\mathrm{P}=0.20$ ). Multivariable Cox regression was additionally performed for this matched subset including the covariate race/ethnicity (as this variable had residual standardized bias $>5 \%$ after matching), which yielded a HR 1.32 (CI: 0.79-2.22, $\mathrm{P}=0.30$ ). In this matched early concurrent chemotherapy subset, median follow-up times were 45.5 (CI: 32.3-77.0) months for patients who received standard RT and 47.5 (CI: 32.1-74.7) months for patients who received HFRT. Figure $3 A, 3 B$ and Table 2 display survival data for the nonmatched and matched groups of patients who received early concurrent chemotherapy, respectively.

In contrast, among non-matched patients who received non-early concurrent chemotherapy $(\mathrm{N}=2,006)$, standard RT $(\mathrm{N}=1,927)$ was significantly associated with numerically shorter OS compared HFRT (N=79) on UVA [18.5 months (CI: 17.4-19.5) vs. 29.5 months (CI: 19.7-37.7), log-rank
$\mathrm{P}=0.027$; HR 0.74, CI: 0.57-0.97, $\mathrm{P}=0.028$ ], although this finding was non-significant on MVA (HR 0.81, CI: 0.62$1.06, \mathrm{P}=0.12)$. The median follow-up times in the nonmatched non-early concurrent chemotherapy subset were 59.8 (CI: 55.7-65.1) and 62.8 (CI: 41.1-79.5) months for patients who received standard RT and HFRT, respectively. Among the matched subset of patients who received nonearly concurrent chemotherapy $(\mathrm{N}=154)$, those who received standard RT had numerically shorter OS (18.6 months, CI: 15.0-21.5 months) compared to those who received HFRT (30.0 months, CI: 21.4-37.7 months), although this finding was also non-significant (stratified log-rank $\mathrm{P}=0.075)$. Stratified univariable Cox regression yielded a HR of 0.65 (CI: 0.40-1.05, $\mathrm{P}=0.077$ ). The median follow-up times for patients in this non-early concurrent chemotherapy matched subset were 52.4 (CI: 38.7-72.6) and 62.8 (41.1-79.5) months for those who received standard RT vs. HFRT, respectively. Figure $4 A, 4 B$ and Table 3 display survival data for the non-matched and matched groups of patients who received non-early concurrent chemotherapy, respectively.

\section{Sensitivity analysis}

Using a cutoff of 60 days rather than 30 days to define early concurrent chemotherapy, OS continued to be numerically longer in those who received standard RT $(\mathrm{N}=6,175)$ compared to HFRT $(\mathrm{N}=93)$ in the subset of patients who underwent early concurrent chemotherapy $(\mathrm{N}=6,268)$. This finding was non-significant on UVA [21.6 months 
Table 2 Univariable and multivariable Cox regression analysis for variables potentially associated with overall survival in non-matched patients $(\mathrm{N}=5,137)$ and matched patients $(\mathrm{N}=138)$ who received early concurrent chemoradiotherapy

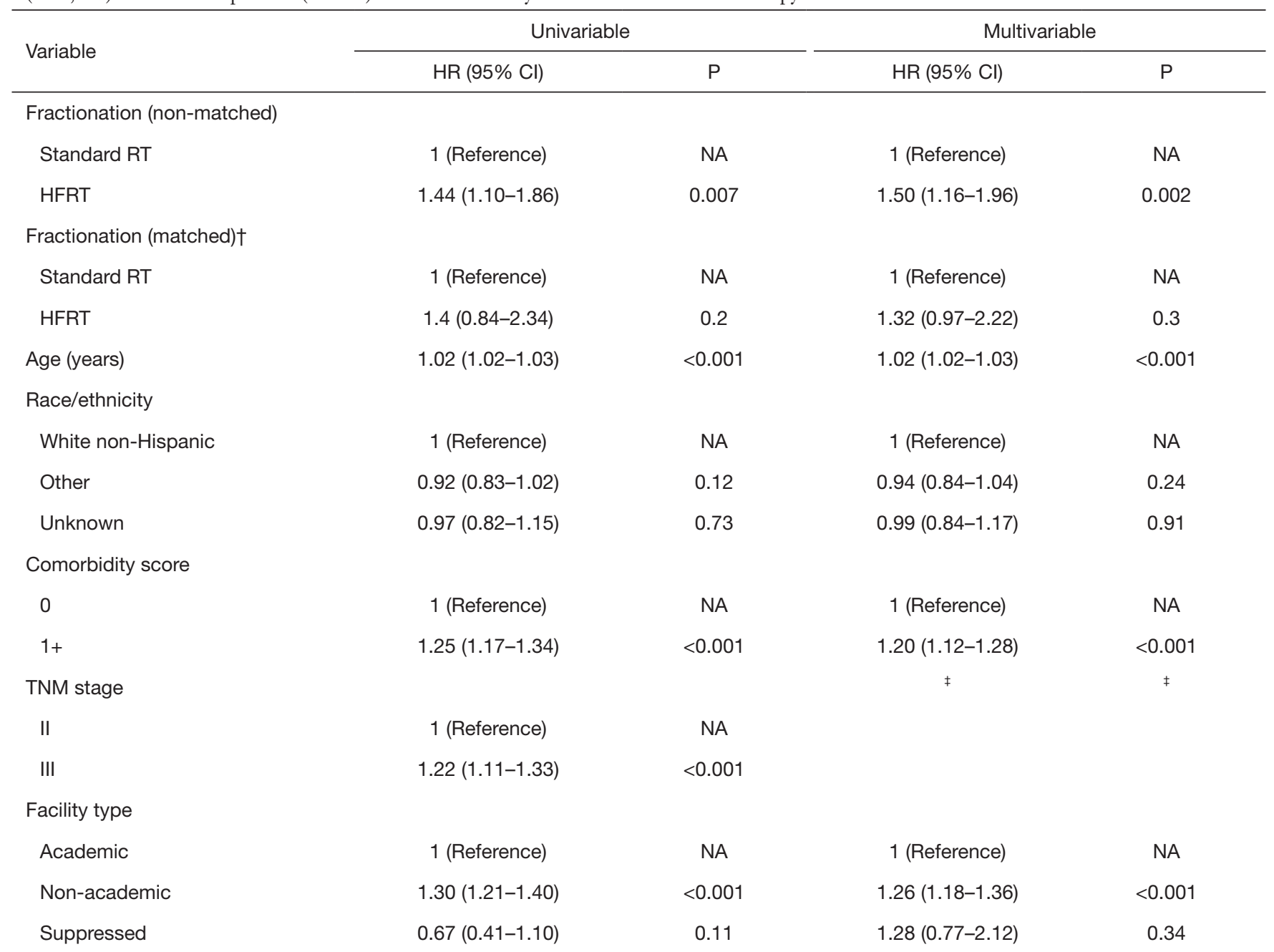

${ }^{\dagger}$, Cox regression stratified by matched pairs. ${ }^{\ddagger}$, final MVA model stratified by TNM stage. HR, hazard ratio; Cl, Confidence Interval; RT, radiation therapy; HFRT, hypofractionated radiation therapy.

(CI: 21.1-22.4) vs. 18.6 months (CI: 14.6-23.6), log-rank $\mathrm{P}=0.21$; HR 1.16, CI: $0.92-1.47, \mathrm{P}=0.21$ ], but significant on MVA (HR 1.29, CI: 1.01-1.64, $\mathrm{P}=0.036$ ). Median follow-up times in this subset were 51.9 (CI: 50.6-53.6) and 55.1 (CI: 40.7-71.2) months among patients who received standard RT and HFRT, respectively. After PSM in this subset ( $\mathrm{N}=180)$, median OS was numerically longer in patients who received standard therapy compared to HFRT although this was non-significant on both univariable [27.2 months (CI: 19.0-33.7) vs. 18.6 months (CI: 14.6-23.6), stratified log-rank $\mathrm{P}=0.22$; HR 1.31 (CI: 0.85-2.04), $\mathrm{P}=0.22$ ] and multivariable (HR 1.26, CI: 0.81-1.96, $\mathrm{P}=0.31$ ) analysis. Median follow-up times in this matched subset were 59.4
(39.3-76.8) and 55.1 (CI: 40.7-71.2) months among patients receiving standard RT $v s$. HFRT, respectively.

In the subset of patients who underwent non-early concurrent chemotherapy using a cutoff of 60 days $(\mathrm{N}=875)$, median OS was found to be non-significantly decreased in patients undergoing standard treatment $(\mathrm{N}=817)$ compared to HFRT (N=58) on UVA [17.3 months (CI: 16.2-18.7) vs. 23.2 months (CI: 15.7-33.6), log rank $\mathrm{P}=0.074$; HR 0.76 (CI: 0.56-1.03), $\mathrm{P}=0.075$ ] and MVA [HR 0.80 (CI: 0.591.110), $\mathrm{P}=0.18]$. Median follow-up times in this subset were

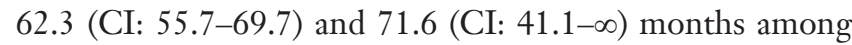
patients who received standard RT and HFRT, respectively. After performing PSM in this subset of patients $(\mathrm{N}=114)$, 

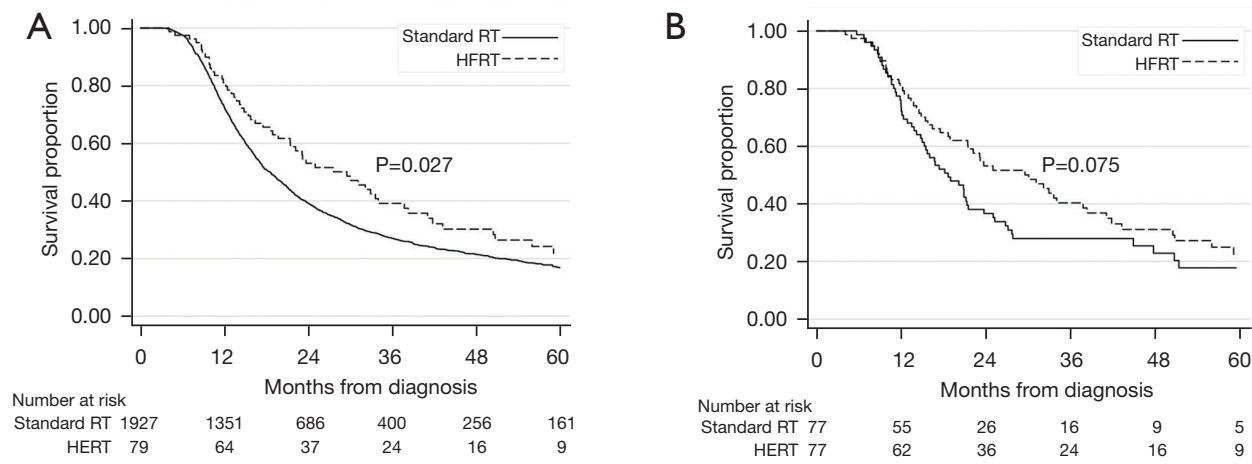

Figure 4 Overall survival comparison with 60 months follow-up by type of radiation received among patients who underwent non-early concurrent chemotherapy. (A) Overall survival comparison between standard radiation (standard RT) vs. hypofractionated radiation therapy (HFRT) in the non-matched subset of patients who received non-early concurrent chemotherapy (N=2,006). (B) Overall survival comparison between standard radiation (standard RT) $v$ s. hypofractionated radiation therapy (HFRT) in the propensity score matched subset of patients who received non-early concurrent chemotherapy $(\mathrm{N}=154)$.

this difference in survival remained non-significant: 21.3 months (CI: 16.1-36.1) for standard RT vs. 23.2 (CI: 15.7-33.6) for HFRT (stratified $\log$ rank $\mathrm{P}=0.77$ ). HRs for univariable and multivariable stratified Cox regressions were 1.09 (CI: 0.61-1.95, P=0.77) and 1.07 (CI: 0.60-1.93, $\mathrm{P}=0.81$ ) for HFRT, respectively. Median follow-up times in this matched subset were 59.4 (CI: 42.5-83.2) and 71.6

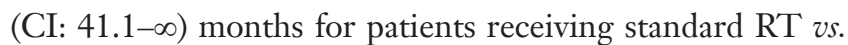
HFRT, respectively.

\section{Discussion}

While the current standard of care for locally advanced LS-SCLC in the US includes chemotherapy and RT to 45 Gy in 30 twice-daily fractions or 60-70 Gy in 30-35 daily fractions, there has been increasing interest in the role of HFRT in this setting, particularly in the context of the COVID-19 pandemic. Our results suggest that there is no overt detriment in OS with HFRT compared to standard RT with concurrent chemotherapy in patients with unresected locally advanced LS-SCLC. Further, the timing of chemotherapy relative to RT may potentially modify the effect of fractionation schedule on survival, although this finding could in part be due to unaccounted differences in characteristics between patients who received early concurrent vs. late concurrent chemotherapy. While median OS was more than six months longer with standard RT compared to HFRT among the non-matched subset of patients who received early concurrent chemotherapy, median OS was eleven months shorter with standard
RT compared to HFRT among the non-matched subset who received non-early concurrent chemotherapy. These differences did not reach statistical significance in our PSM analyses, although our relatively small sample size limits the power of our analysis. Given the increased convenience and decreased resource utilization with HFRT as well as the precedent for HFRT being the most frequently used regimen in Canada and the United Kingdom, HFRT may be a reasonable option in locally advanced LS-SCLC, particularly in patients unable to undergo early concurrent chemoradiotherapy (9).

While there have been no prior published large national database analyses on this subject, a number of smaller institutional studies have investigated HFRT compared to standard RT in LS-SCLC, usually reporting comparable outcomes and toxicity between the two treatments (11-14,19). While several different fractionation schedules for HFRT have been explored, 40-45 Gy in 15 fractions remains most popular in Canada and the United Kingdom (9). Given the significant potential for selection bias with such small sample sizes and with retrospective studies, Zayed et al. recently performed a PSM institutional analysis of 72 patients who received HFRT (40 Gy/ 15 fractions, 45 Gy/15 fractions, or 45 Gy/20 fractions) or CFRT (60 Gy/30 or 66 Gy/33 fractions) for LS-SCLC, demonstrating no difference in PFS, OS, or pulmonary or esophageal adverse events between the two groups (15). Similarly, Yan et al. performed an PSM-adjusted biinstitutional retrospective analysis comparing HFRT (40 Gy/15 fractions) with accelerated RT (45 Gy/30 BID 
Table 3 Univariable and multivariable Cox regression analysis for variables potentially associated with overall survival in non-matched patients $(\mathrm{N}=2,006)$ and matched patients $(\mathrm{N}=154)$ who received non-early concurrent chemoradiotherapy

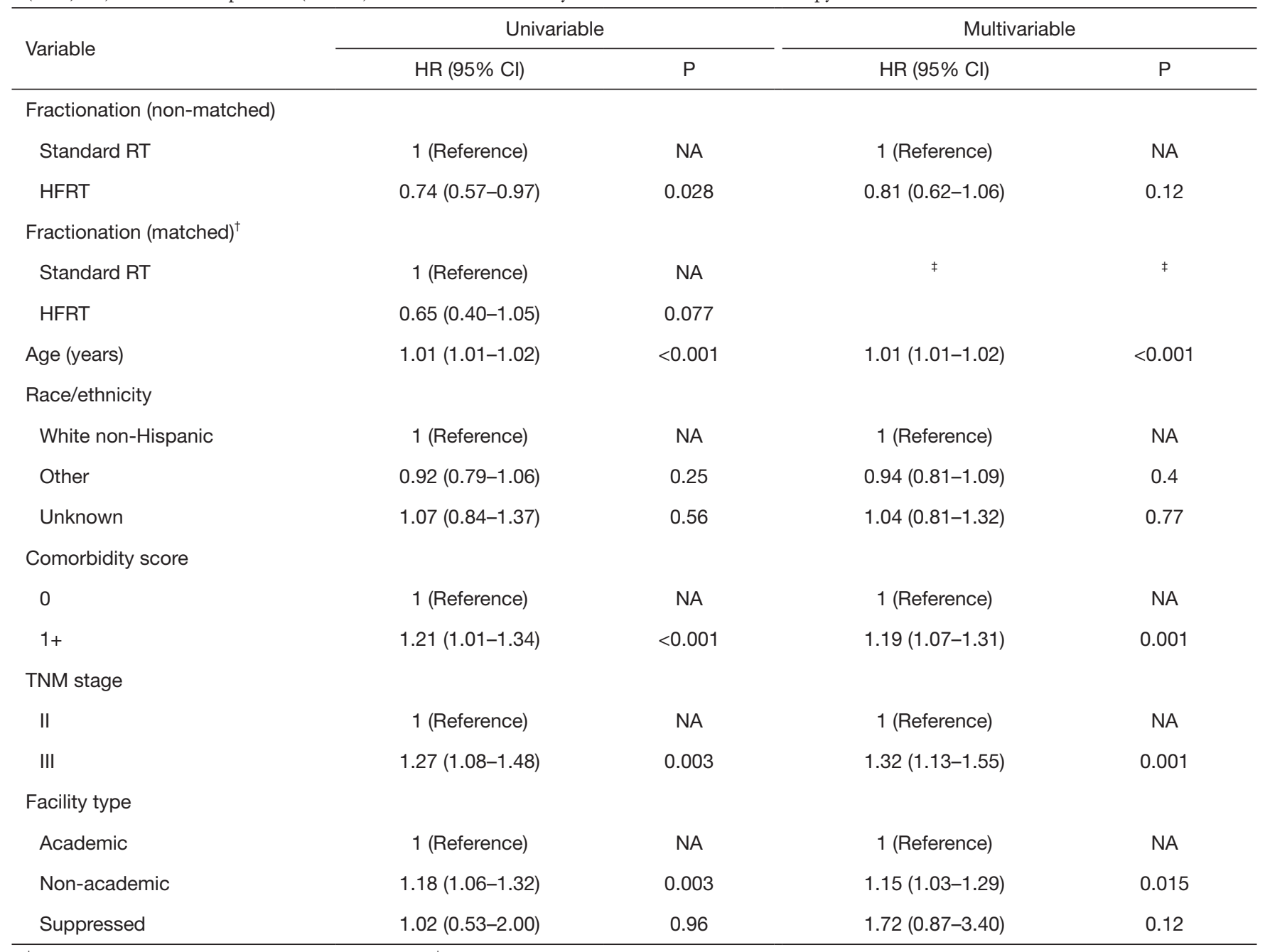

${ }^{\dagger}$, Cox regression stratified by matched pairs; ${ }^{\ddagger}$, multivariable analysis not performed in matched cohort. HR, hazard ratio; Cl, confidence interval; RT, radiation therapy; HFRT, hypofractionated radiation therapy.

fractions) using with overlap weighting for clinical and treatment variables; among the 173 patients included in their analysis (63 HFRT and 110 accelerated RT), there were no significant differences in OS, thoracic response, locoregional recurrence risk, or grade 3+ toxicity (19). In our own study, PSM analysis was performed as a sensitivity analysis to reduce the effect of potential confounders, with no significant differences in survival between HFRT and standard RT in our primary cohort.

While prospective randomized data in this setting remains limited, a randomized phase II trial by Grønberg et al. comparing $45 \mathrm{~Gy}$ in 30 fractions vs. $42 \mathrm{~Gy}$ in 15 fractions with cisplatin/etoposide in 157 patients with
LS-SCLC reported similar median PFS and comparable severe toxicity between the two arms, although accelerated RT was associated with a non-significant increase in OS (25.1 vs. 18.8 months, $\mathrm{P}=0.61$ ) and significantly higher complete response ( $33 \%$ vs. $13 \%, \mathrm{P}=0.003)(10) .55 \mathrm{~Gy}$ in 22 fractions and 65 Gy in 26 fractions have also been explored prospectively with favorable outcomes and acceptable toxicity, although these fractionation schedules are less popular in Western countries (16-18). We were unable to examine $65 \mathrm{~Gy}$ in 26 fractions as there were no patients in the NCDB who received this regimen; only four patients received 55 Gy in 22 fractions and were thus excluded from our analysis. Still, given the limited 
prospective evidence for HFRT over standard RT for LSSCLC, HFRT is not routinely recommended in the US $(2,28)$. The results of our analysis are largely consistent with those demonstrated by smaller institutional studies; that is, HFRT results in no statistically significant worse survival compared to standard RT, now demonstrated on a national scale.

HFRT offers a number of unique advantages over standard RT. HFRT is likely more convenient than standard RT-especially compared to twice-daily fractionation. With less traveling and lost time from work, patients may face a smaller financial burden with treatments consisting of fewer fractions $(29,30)$. HFRT may also be utilized when there is limited machine and/or department capacity (31). HFRT may have greater cost-effectiveness in public-payer systems such as those of the United Kingdom or Canada where this regimen is widely used; with the recent Medicare and Medicaid transition from a fee-for-service reimbursement system to bundled payments, HFRT may have a similar financial incentive in the US (29-30,32-35). Additionally, it is pertinent to highlight the benefit of RT schedules consisting of fewer fractions when appropriate during the COVID-19 pandemic, which may reduce the risk of exposure in this particularly vulnerable group of patients (6,36-38). The updated joint practice recommendations of the European Society for Radiotherapy and Oncology (ESTRO) and American Society for Radiation Oncology (ASTRO) considers both an early and late phase of the pandemic with regards to lung cancer RT, characterized first by risk mitigation through limiting contact and later by reduced resources requiring triage, respectively (38). The recommendation regarding HFRT in this later stage of the pandemic for LS-SCLC consists of 45 Gy in 15 fractions. Our findings suggest that select patients may possibly be considered for HFRT in this setting.

Importantly, our analysis suggests that the timing of concurrent chemotherapy in relation to the start of RT may influence the impact of fractionation schedule on survival in early-stage SCLC. Early administration of concurrent chemoradiation in this setting has been associated with improved locoregional control and survival in a number of studies, although some recent limited data has called this benefit into question (14,39-43). Interestingly, our analysis demonstrated worsened OS with HFRT compared to standard RT among those who underwent early concurrent chemoradiation, but improved OS with HFRT compared to standard RT among those who underwent non-early concurrent chemoradiation, although neither of these findings quite reached statistical significance in our matched sensitivity analyses. The time interval between start of any treatment until the end of RT (SER) may partially explain these findings, given the association of this interval with improved survival in LS-SCLC $(2,44,45)$. Notably, the time to start of RT in our cohort was longer in patients who received HFRT compared to those who received standard RT, possibly indicating a poor response to chemotherapy in the HFRT group or possible ambiguity in distinguishing limited $v s$. extensive disease on imaging leading to delays in starting RT. Moreover, the group of patients who received early concurrent chemotherapy (the preferred timing for chemotherapy) along with standard RT may represent a group with better performance status compared to those patients who were selected to receive non-standard therapy. This former standard treatment group may have benefited from a full course of standard RT, whereas patients who received HFRT and sequential chemotherapy may have been ineligible for early concurrent chemotherapy based on performance status or disease burden. In these patients, less aggressive RT with a lower biologically effective dose and possibly less toxicity may potentially be beneficial. Additionally, without the benefit of radio-sensitization with early concurrent chemotherapy, a shorter course of radiation treatment (with a shorter SER) may account for the improved survival with HFRT in the non-early concurrent chemotherapy subset. However, the relationship between chemotherapy timing and fractionation schedule in LS-SCLC must be studied in greater detail, with future prospective studies stratifying patients based on timing of concurrent chemotherapy in this setting.

Our findings suggest that standard RT with concurrent chemotherapy is likely preferred in those patients who are able to receive early concurrent administration of both therapies; however, HFRT appears to be no worse compared to standard RT and perhaps even beneficial in patients who are unable to receive early concurrent chemotherapy with RT. This is particularly relevant during the COVID-19 pandemic, during which treatment delays and increased logistic barriers to travel are not uncommon. The relationship between fractionation schedule and timing of chemotherapy, and its impact on survival, should be prospectively explored.

Additionally, our analysis did not demonstrate a significant interaction between fractionation and disease stage, suggesting that HFRT may be considered in stage II or III disease. It is worth considering the potential role of HFRT in this setting with improvements in systemic 
control with immunotherapy. Phase II data from the NRG LU005 study of concurrent chemoradiation and pembrolizumab in LS-SCLC demonstrates acceptable toxicity and favorable outcomes (median PFS 19.7 months; median OS 39.5 months) (46). The role of higher doseper-fraction (such as with HFRT) vs. standard fractionation with dose escalation [as has been recently explored by Grønberg et al. (47)] to provide adequate local control in an age of improved systemic control should continue to be prospectively explored.

There are notable limitations to this study, including selection bias given the retrospective nature of our analysis and small sample size bias in comparing our small HFRT groups to the much larger standard RT groups. However, we attempted to balance baseline characteristics and thus reduce the impact of confounding on our results with PSM. Still, there may be unmeasured confounders from certain characteristics not included in the NCDB, including central $v s$. peripheral tumor location, performance status, smoking status, number of chemotherapy cycles received, and more specific information regarding modalities used in staging such as PET imaging, brain MRI, and invasive mediastinal staging $(15,19)$. The non-early concurrent chemotherapy group could potentially represent a less favorable population based on these confounders, contributing to the correlation with HFRT in this group and perhaps limiting the generalizability of our results. Additionally, there is variability in the coding of certain demographic and clinical variables in the NCDB as well as a lack of data on locoregional control or toxicity in this database. There was also no reliable information regarding the use of prophylactic cranial irradiation (PCI) in our study population. Nevertheless, this analysis was comprised of a large national patient cohort compared to the small sample sizes of prior institutional studies, likely representing the largest study of patients receiving HFRT in this setting in the US while still including extensive sociodemographic and treatment-related variables.

\section{Conclusions}

The results of our study demonstrate that HFRT with concurrent chemotherapy is associated with no worse survival than standard RT with concurrent chemotherapy in patients with unresected locally advanced LS-SCLC. While HFRT is rarely used in the United States in this setting, it is the preferred regimen in many countries including the United Kingdom and Canada. Given its increased convenience, decreased costs, and reduced resource utilization, HFRT may be considered in place of standard RT, especially for patients unable to receive early concurrent chemoradiation. Prospective studies are needed to explore local control and toxicity associated with HFRT in this setting.

\section{Acknowledgments}

These findings are scheduled to be presented at the $103^{\text {rd }}$ Annual Meeting of the American Radium Society from September $29^{\text {th }}$-October $1^{\text {st }}, 2021$ (conference originally scheduled to be held in Maui, HI, but switched to virtual). Funding: This work was supported by the Yale School of Medicine Medical Student Research Fellowship (granted to N.A.S.). This entity had no involvement in study design; in the collection, analysis and interpretation of data; in the writing of the report; and in the decision to submit the article for publication.

\section{Footnote}

Reporting Checklist: The authors have completed the STROBE reporting checklist. Available at https://jtd. amegroups.com/article/view/10.21037/jtd-21-1566/rc

Peer Review File: Available at https://jtd.amegroups.com/ article/view/10.21037/jtd-21-1566/prf

Conflicts of Interest: All authors have completed the ICMJE uniform disclosure form (available at https://jtd.amegroups. com/article/view/10.21037/jtd-21-1566/coif). LJ became a full-time employee at Sema4 on September 20, 2021. RHD reports the following conflicts of interest: Merck \& Co., Inc (research grants, advisory board), AstraZeneca (consultant, travel expenses, speaker's bureau, advisory board), Regeneron (consultant, travel expenses, advisory board), Novocure (advisory board), Physician Education Resource (Honoraria, travel expenses), and PeerView (Honoraria, travel expenses). HSP reports relationships not relevant to the current work: AstraZeneca (consulting fees), Bristol Myers Squibb (speaking fees/honoraria), Galera Therapeutics (advisory board fees), Guidepoint (honoraria), Grand Rounds Health (honoraria), Healthcasts (honoraria), Healthline (honoraria), Rad Onc Questions (honoraria), RefleXion Medical (research funds), and United States Food and Drug Administration (research funds). HSP serves as an unpaid editorial board member of fournal of 
Thoracic Disease from September 2016 to September 2023. The other authors have no conflicts of interest to declare.

Ethical Statement: The authors are accountable for all aspects of the work in ensuring that questions related to the accuracy or integrity of any part of the work are appropriately investigated and resolved. This study was conducted in accordance with the Declaration of Helsinki (as revised in 2013). As all patient information was deidentified, this study was exempt from institutional review board approval (Yale) and informed consent.

Disclaimer: The American College of Surgeons and the Commission on Cancer have not verified and are not responsible for the analytic or statistical methodology used, or for the conclusions drawn, from these data by the investigators.

Open Access Statement: This is an Open Access article distributed in accordance with the Creative Commons Attribution-NonCommercial-NoDerivs 4.0 International License (CC BY-NC-ND 4.0), which permits the noncommercial replication and distribution of the article with the strict proviso that no changes or edits are made and the original work is properly cited (including links to both the formal publication through the relevant DOI and the license). See: https://creativecommons.org/licenses/by-nc-nd/4.0/.

\section{References}

1. Chun SG, Simone CB 2nd, Amini A, et al. American Radium Society Appropriate Use Criteria: Radiation Therapy for Limited-Stage SCLC 2020. J Thorac Oncol 2021;16:66-75.

2. National Comprehensive Cancer Network. NCCN Clinical Practice Guidelines in Oncology: Small Cell Lung Cancer (Version 1.2021). Available online: https://www. nccn.org/professionals/physician_gls/pdf/sclc_blocks.pdf. Accessed Nov 4, 2020.

3. Turrisi AT 3rd, Kim K, Blum R, et al. Twice-daily compared with once-daily thoracic radiotherapy in limited small-cell lung cancer treated concurrently with cisplatin and etoposide. N Engl J Med 1999;340:265-71.

4. Faivre-Finn C, Snee M, Ashcroft L, et al. Concurrent once-daily versus twice-daily chemoradiotherapy in patients with limited-stage small-cell lung cancer (CONVERT): an open-label, phase 3, randomised, superiority trial. Lancet Oncol 2017;18:1116-25.
5. Bogart JA, Wang XF, Masters GA, et al. Phase 3 comparison of high-dose once-daily (QD) thoracic radiotherapy (TRT) with standard twice-daily (BID) TRT in limited stage small cell lung cancer (LSCLC): CALGB 30610 (Alliance)/RTOG 0538. J Clin Oncol 2021;39:8505.

6. Faivre-Finn C, Fenwick JD, Franks KN, et al. Reduced Fractionation in Lung Cancer Patients Treated with Curative-intent Radiotherapy during the COVID-19 Pandemic. Clin Oncol (R Coll Radiol) 2020;32:481-9.

7. Amini A, Lin SH, Wei C, et al. Accelerated hypofractionated radiation therapy compared to conventionally fractionated radiation therapy for the treatment of inoperable non-small cell lung cancer. Radiat Oncol 2012;7:33.

8. Westover KD, Loo BW Jr, Gerber DE, et al. Precision Hypofractionated Radiation Therapy in Poor Performing Patients With Non-Small Cell Lung Cancer: Phase 1 Dose Escalation Trial. Int J Radiat Oncol Biol Phys 2015;93:72-81.

9. Shahi J, Wright JR, Gabos Z, et al. Management of smallcell lung cancer with radiotherapy-a pan-Canadian survey of radiation oncologists. Curr Oncol 2016;23:184-95.

10. Grønberg BH, Halvorsen TO, Fløtten Ø, et al. Randomized phase II trial comparing twice daily hyperfractionated with once daily hypofractionated thoracic radiotherapy in limited disease small cell lung cancer. Acta Oncol 2016;55:591-7.

11. Videtic GM, Truong PT, Dar AR, et al. Shifting from hypofractionated to "conventionally" fractionated thoracic radiotherapy: a single institution's 10 -year experience in the management of limited-stage small-cell lung cancer using concurrent chemoradiation. Int J Radiat Oncol Biol Phys 2003;57:709-16.

12. Turgeon GA, Souhami L, Kopek N, et al. Thoracic irradiation in 3weeks for limited-stage small cell lung cancer: Is twice a day fractionation really needed? Cancer Radiother 2017;21:89-98.

13. Bettington CS, Tripcony L, Bryant G, et al. A retrospective analysis of survival outcomes for two different radiotherapy fractionation schedules given in the same overall time for limited stage small cell lung cancer. J Med Imaging Radiat Oncol 2013;57:105-12.

14. Socha J, Guzowska A, Tyc-Szczepaniak D, et al. Accelerated hypofractionated thoracic radiotherapy in limited disease small cell lung cancer : comparison with the results of conventionally fractionated radiotherapy. J BUON 2015;20:146-57.

15. Zayed S, Chen H, Ali E, et al. Is There a Role for 
Hypofractionated Thoracic Radiation Therapy in Limited-Stage Small Cell Lung Cancer? A Propensity Score Matched Analysis. Int J Radiat Oncol Biol Phys 2020;108:575-86.

16. Hu X, Xia B, Bao Y, et al. Timing of thoracic radiotherapy is more important than dose intensification in patients with limited-stage small cell lung cancer: a parallel comparison of two prospective studies. Strahlenther Onkol 2020;196:172-81.

17. Xia B, Hong LZ, Cai XW, et al. Phase 2 study of accelerated hypofractionated thoracic radiation therapy and concurrent chemotherapy in patients with limitedstage small-cell lung cancer. Int J Radiat Oncol Biol Phys 2015;91:517-23

18. Qiu B, Li Q, Liu J, et al. Moderately Hypofractionated Once-Daily Compared With Twice-Daily Thoracic Radiation Therapy Concurrently With Etoposide and Cisplatin in Limited-Stage Small Cell Lung Cancer: A Multicenter, Phase II, Randomized Trial. Int J Radiat Oncol Biol Phys 2021;111:424-35.

19. Yan M, Sigurdson S, Greifer N, et al. A Comparison of Hypofractionated and Twice-Daily Thoracic Irradiation in Limited-Stage Small-Cell Lung Cancer: An OverlapWeighted Analysis. Cancers (Basel) 2021;13:2895.

20. American College of Surgeons. SMALL National Cancer Database. Available online: https://www.facs.org/qualityprograms/cancer/ncdb/puf. 2021

21. American College of Surgeons. National Cancer Database. Available online: https://www.facs.org/quality-programs/ cancer/ncdb. Accessed October 28, 2020.

22. Austin PC. The use of propensity score methods with survival or time-to-event outcomes: reporting measures of effect similar to those used in randomized experiments. Stat Med 2014;33:1242-58.

23. Austin PC. Optimal caliper widths for propensity-score matching when estimating differences in means and differences in proportions in observational studies. Pharm Stat 2011;10:150-61.

24. Caliendo M, Kopeinig S. Some practical guidance for the implementation of propensity score matching. J Econ Surv 2008;22:31-72.

25. Austin PC, Fine JP. Propensity-score matching with competing risks in survival analysis. Stat Med 2019;38:751-77.

26. Austin PC. A Tutorial and Case Study in Propensity Score Analysis: An Application to Estimating the Effect of InHospital Smoking Cessation Counseling on Mortality. Multivariate Behav Res 2011;46:119-51.
27. Nguyen TL, Collins GS, Spence J, et al. Doubleadjustment in propensity score matching analysis: choosing a threshold for considering residual imbalance. BMC Med Res Methodol 2017;17:78.

28. Simone CB 2nd, Bogart JA, Cabrera AR, et al. Radiation Therapy for Small Cell Lung Cancer: An ASTRO Clinical Practice Guideline. Pract Radiat Oncol 2020;10:158-73.

29. Hunter D, Mauldon E, Anderson N. Cost-containment in hypofractionated radiation therapy: a literature review. J Med Radiat Sci 2018;65:148-57.

30. Deshmukh AA, Shirvani SM, Lal L, et al. Costeffectiveness Analysis Comparing Conventional, Hypofractionated, and Intraoperative Radiotherapy for Early-Stage Breast Cancer. J Natl Cancer Inst 2017;109. doi: 10.1093/jnci/djx068.

31. Glatzer M, Faivre-Finn C, De Ruysscher D, et al. Once daily versus twice-daily radiotherapy in the management of limited disease small cell lung cancer - Decision criteria in routine practise. Radiother Oncol 2020;150:26-9.

32. Lievens Y. Hypofractionated breast radiotherapy: financial and economic consequences. Breast 2010;19:192-7.

33. Aneja S, Pratiwadi RR, Yu JB. Hypofractionated radiation therapy for prostate cancer: risks and potential benefits in a fiscally conservative health care system. Oncology (Williston Park) 2012;26:512-8.

34. Mitera G, Swaminath A, Rudoler D, et al. Costeffectiveness analysis comparing conventional versus stereotactic body radiotherapy for surgically ineligible stage I non-small-cell lung cancer. J Oncol Pract 2014;10:e130-6.

35. Dimitroynnis DA. Modern Hypofractionated Radiation Therapy Offers Improved Patient Outcomes at Reduced Overall Costs: Value-Based Health Care Delivery for Breast, Prostate, and Lung Cancers. Int J Radiat Oncol Biol Phys 2016;96:E410.

36. Kumar S, Chmura S, Robinson C, et al. Alternative Multidisciplinary Management Options for Locally Advanced NSCLC During the Coronavirus Disease 2019 Global Pandemic. J Thorac Oncol 2020;15:1137-46.

37. Wei W, Zheng D, Lei Y, et al. Radiotherapy workflow and protection procedures during the Coronavirus Disease 2019 (COVID-19) outbreak: Experience of the Hubei Cancer Hospital in Wuhan, China. Radiother Oncol 2020;148:203-10.

38. Guckenberger M, Belka C, Bezjak A, et al. Practice Recommendations for Lung Cancer Radiotherapy During the COVID-19 Pandemic: An ESTRO-ASTRO Consensus Statement. Int J Radiat Oncol Biol Phys 
2020;107:631-40.

39. Jett JR, Schild SE, Kesler KA, et al. Treatment of small cell lung cancer: Diagnosis and management of lung cancer, 3rd ed: American College of Chest Physicians evidence-based clinical practice guidelines. Chest 2013;143:e400S-19S.

40. Murray N, Coy P, Pater JL, et al. Importance of timing for thoracic irradiation in the combined modality treatment of limited-stage small-cell lung cancer. The National Cancer Institute of Canada Clinical Trials Group. J Clin Oncol 1993;11:336-44.

41. Fried DB, Morris DE, Poole C, et al. Systematic review evaluating the timing of thoracic radiation therapy in combined modality therapy for limited-stage small-cell lung cancer. J Clin Oncol 2004;22:4837-45.

42. Bhandari S, Pham D, Pinkston C, et al. Timing of treatment in small-cell lung cancer. Med Oncol 2019;36:47.

43. Farrell MJ, Yahya JB, Degnin C, et al. Timing of Thoracic Radiation Therapy With Chemotherapy in Limited-

Cite this article as: Saeed NA, Jin L, Sasse AW, Amini A, Verma V, Lester-Coll NH, Chen PH, Decker RH, Park HS. Hypofractionated vs. standard radiotherapy for locally advanced limited-stage small cell lung cancer. J Thorac Dis 2022;14(2):306-320. doi: 10.21037/jtd-21-1566 stage Small-cell Lung Cancer: Survey of US Radiation Oncologists on Current Practice Patterns. Clin Lung Cancer 2018;19:e815-21.

44. De Ruysscher D, Pijls-Johannesma M, Bentzen SM, et al. Time between the first day of chemotherapy and the last day of chest radiation is the most important predictor of survival in limited-disease small-cell lung cancer. J Clin Oncol 2006;24:1057-63.

45. Kalemkerian GP. Advances in the treatment of small-cell lung cancer. Semin Respir Crit Care Med 2011;32:94-101.

46. Welsh JW, Heymach JV, Guo C, et al. Phase 1/2 Trial of Pembrolizumab and Concurrent Chemoradiation Therapy for Limited-Stage SCLC. J Thorac Oncol 2020;15:1919-27.

47. Grønberg BH, Killingberg KT, Fløtten $\varnothing$, et al. High-dose versus standard-dose twice-daily thoracic radiotherapy for patients with limited stage small-cell lung cancer: an open-label, randomised, phase 2 trial. Lancet Oncol 2021;22:321-31. 
Table S1 Demographic and clinical characteristics of patients receiving standard radiation therapy $v s$. hypofractionated radiation therapy among the whole cohort $(\mathrm{N}=7,143)$

\begin{tabular}{|c|c|c|c|}
\hline Variable $(\mathrm{N})$ & Standard RT & HFRT & $P^{*}$ \\
\hline No. (\%) of patients & 6992 & 151 & \\
\hline Age (years), mean \pm SE & $64.0 \pm 0.11$ & $65.0 \pm 0.79$ & 0.18 \\
\hline Age (years) & & & 0.23 \\
\hline$\leq 64(3613)$ & $3544(50.7)$ & $69(45.7)$ & \\
\hline$>64(3530)$ & 3448 (49.3) & $82(54.3)$ & \\
\hline Sex & & & 0.067 \\
\hline Male (3120) & $3043(43.5)$ & $77(51.0)$ & \\
\hline Female (4023) & 3949 (56.5) & $74(49.0)$ & \\
\hline Race/Ethnicity & & & 0.073 \\
\hline White non-Hispanic (6022) & $5900(84.4)$ & $122(80.8)$ & \\
\hline Other (839) & $813(11.6)$ & $26(17.2)$ & \\
\hline Unknown (282) & $279(4.0)$ & $3(2.0)$ & \\
\hline Income & & & 0.51 \\
\hline$<50 \%$ (3203) & $3133(44.8)$ & $70(46.4)$ & \\
\hline$\geq 50 \%$ (3382) & 3309 (47.3) & $73(48.3)$ & \\
\hline Not available (558) & $550(7.9)$ & $8(5.3)$ & \\
\hline Insurance & & & 0.76 \\
\hline None/Non-Private (4678) & 4575 (65.4) & $103(68.2)$ & \\
\hline Private (2371) & $2324(33.2)$ & $47(31.1)$ & \\
\hline Unknown (94) & $93(1.3)$ & $1(0.7)$ & \\
\hline Medicaid expansion state status & & & $<0.001$ \\
\hline Non-expansion (2765) & $2735(39.1)$ & 30 (19.9) & \\
\hline Expansion (4337) & $4217(60.3)$ & $120(79.5)$ & \\
\hline Suppressed (41) & $40(0.6)$ & $1(0.7)$ & \\
\hline Urban/Rural & & & $<0.001$ \\
\hline Metro 250k+ (4607) & $4487(64.2)$ & $120(79.5)$ & \\
\hline Other area (2339) & 2369 (33.9) & 30 (19.9) & \\
\hline Not available (137) & $136(2.0)$ & $1(0.7)$ & \\
\hline Greater Circle Distance & & & 0.43 \\
\hline$\leq 10 \mathrm{mi}(3225)$ & $3161(45.2)$ & $64(42.4)$ & \\
\hline >10 mi (3406) & 3327 (47.6) & $79(52.3)$ & \\
\hline Unknown (512) & $504(7.2)$ & $8(5.3)$ & \\
\hline Year of diagnosis, mean \pm SE & $2013 \pm 0.029$ & $2013 \pm 0.18$ & 0.43 \\
\hline Comorbidity Score & & & 0.88 \\
\hline $0(4158)$ & $4071(58.2)$ & $87(57.6)$ & \\
\hline $1+(2985)$ & $2921(41.8)$ & $64(42.4)$ & \\
\hline Concurrent chemotherapy & & & $<0.001$ \\
\hline Early Concurrent (5137) & 5065 (72.4) & $72(47.7)$ & \\
\hline Non-early concurrent (2006) & $1927(27.6)$ & 79 (52.3) & \\
\hline
\end{tabular}

Table S1 (continued) 
Table S1 (continued)

\begin{tabular}{|c|c|c|c|}
\hline Variable $(\mathrm{N})$ & Standard RT & HFRT & $P^{*}$ \\
\hline Tumor location & & & 0.96 \\
\hline Right (3700) & $3620(51.8)$ & $80(53.0)$ & \\
\hline Left (2679) & $2624(37.5)$ & $55(36.4)$ & \\
\hline Other/unknown (764) & $748(10.7)$ & $16(10.6)$ & \\
\hline Grade & & & 0.13 \\
\hline Well/mod/intermediate (29) & $28(0.4)$ & $1(0.66)$ & \\
\hline Poor/undifferentiated (1693) & $1666(23.8)$ & $27(17.9)$ & \\
\hline N/A (5421) & $5298(75.8)$ & $123(81.5)$ & \\
\hline T stage & & & 0.37 \\
\hline T1 (1640) & $1607(23.0)$ & $33(21.9)$ & \\
\hline T2 (2213) & $2171(31.1)$ & $42(27.8)$ & \\
\hline T3 (1439) & $1400(20.0)$ & $39(25.8)$ & \\
\hline $\mathrm{T} 4$ (1851) & $1814(25.9)$ & $37(24.5)$ & \\
\hline $\mathrm{N}$ stage & & & 0.067 \\
\hline N0 (663) & $656(9.4)$ & $7(4.6)$ & \\
\hline N1 (978) & $954(13.6)$ & $24(15.9)$ & \\
\hline N2 (4205) & $4121(58.9)$ & $84(55.6)$ & \\
\hline N3 (1297) & $1261(18.0)$ & $36(23.8)$ & \\
\hline TNM stage & & & 0.77 \\
\hline II (1054) & $1033(14.8)$ & $21(13.9)$ & \\
\hline III (6089) & 5959 (85.2) & $130(86.1)$ & \\
\hline Facility Type & & & $<0.001$ \\
\hline Academic (2265) & $2168(31.0)$ & $97(64.2)$ & \\
\hline Non-academic (4837) & $4784(68.4)$ & $53(35.1)$ & \\
\hline Suppressed (41) & $40(0.6)$ & $1(0.7)$ & \\
\hline Facility Location & & & 0.05 \\
\hline East Coast (3012) & 2962 (42.4) & $50(33.1)$ & \\
\hline All other (4090) & $3990(57.1)$ & $100(66.2)$ & \\
\hline Suppressed (41) & $40(0.6)$ & $1(0.7)$ & \\
\hline
\end{tabular}

${ }^{*} \mathrm{P}$ value reflects chi-square analysis or Fisher's exact test for categorical variables and ANOVA for continuous variables. RT, radiation therapy, HFRT, hypofractionated radiation therapy; SE, standard error. 
Table S2 Univariable and multivariable logistic regression analysis for variables potentially associated with receipt of hypofractionated radiation therapy (HFRT; N=151) compared to standard radiation therapy (standard RT; N=6,992) among the entire cohort $(\mathrm{N}=7,143)$

\begin{tabular}{|c|c|c|c|c|}
\hline \multirow{2}{*}{ Variable $^{\dagger}$} & \multicolumn{2}{|l|}{ Univariable } & \multicolumn{2}{|l|}{ Multivariable } \\
\hline & OR (95\% Cl) & $P$ & OR (95\% Cl) & $P$ \\
\hline \multicolumn{5}{|l|}{ Sex } \\
\hline Male & 1 [Reference] & & 1 [Reference] & NA \\
\hline Female & $0.74(0.54-1.02)$ & 0.068 & $0.76(0.55-1.06)$ & 0.1 \\
\hline Age (years) & $1.01(0.99-1.03)$ & 0.18 & & \\
\hline \multicolumn{5}{|l|}{ Race/Ethnicity } \\
\hline White non-Hispanic & 1 [Reference] & NA & & \\
\hline Other & $1.55(0.95-2.19)$ & 0.047 & & \\
\hline Unknown & $0.52(0.15-1.47)$ & 0.27 & & \\
\hline \multicolumn{5}{|l|}{ Medicaid expansion state status } \\
\hline Non-expansion & 1 [Reference] & NA & 1 [Reference] & NA \\
\hline Expansion & $2.59(1.73-3.88)$ & $<0.001$ & $2.24(1.49-3.37)$ & $<0.001$ \\
\hline Suppressed & $2.28(0.30-17.1)$ & 0.42 & $1.51(0.19-11.7)$ & 0.7 \\
\hline \multicolumn{5}{|l|}{ Urban/Rural } \\
\hline Metro $250 \mathrm{k}+$ & 1 [Reference] & NA & 1 [Reference] & NA \\
\hline Other area & $0.47(0.32-0.71)$ & $<0.001$ & $0.62(0.41-0.95)$ & 0.027 \\
\hline Not available & $0.27(0.038-1.98)$ & 0.2 & $0.32(0.04-2.37)$ & 0.27 \\
\hline \multicolumn{5}{|l|}{ Concurrent chemotherapy } \\
\hline Early concurrent & 1 [Reference] & NA & 1 [Reference] & NA \\
\hline Non-early concurrent & $2.88(2.09-3.99)$ & $<0.001$ & $3.05(2.19-4.24)$ & $<0.001$ \\
\hline \multicolumn{5}{|l|}{ Grade } \\
\hline Well/moderate/intermediate & 1 [Reference] & NA & & \\
\hline Poorly/undifferentiated & $0.45(0.060-3.46)$ & 0.45 & & \\
\hline $\mathrm{N} / \mathrm{A}$ & $0.65(0.087-4.82)$ & 0.67 & & \\
\hline \multicolumn{5}{|l|}{$\mathrm{N}$ stage } \\
\hline No & 1 [Reference] & NA & 1 [Reference] & NA \\
\hline N1 & $2.36(1.01-5.50)$ & 0.047 & $2.70[1.14-6.35]$ & 0.023 \\
\hline N2 & $1.91(0.88-4.15)$ & 0.1 & $2.06[0.94-4.50]$ & 0.07 \\
\hline N3 & $2.68[1.18-6.04]$ & 0.018 & $2.51[1.10-5.72]$ & 0.029 \\
\hline \multicolumn{5}{|l|}{ Facility Type } \\
\hline Academic & 1 [Reference] & NA & 1 [Reference] & NA \\
\hline Non-academic & $0.25(0.18-0.35)$ & $<0.001$ & $0.26(0.18-0.37)$ & $<0.001$ \\
\hline Suppressed & $0.56(0.076-4.11)$ & 0.57 & 1 & NA \\
\hline \multicolumn{5}{|l|}{ Facility Location } \\
\hline East Coast & 1 [Reference] & NA & 1 [Reference] & NA \\
\hline All other & $1.48(1.05-2.09)$ & 0.024 & $1.80(1.26-2.56)$ & 0.001 \\
\hline Suppressed & $1.48(0.20-11.0)$ & 0.7 & 1 & NA \\
\hline
\end{tabular}

\footnotetext{
${ }^{\dagger}$, variables with empty spaces in multivariate column were not included in the final MVA model. OR, odds ratio; $\mathrm{Cl}$, confidence interval.
} 
Table S3 Univariable and multivariable logistic regression analysis for variables potentially associated with receipt of hypofractionated radiation therapy (HFRT; N=72) compared to standard radiation therapy (standard RT; $\mathrm{N}=5,065$ ) among the early concurrent chemotherapy subset $(\mathrm{N}=5,137)$

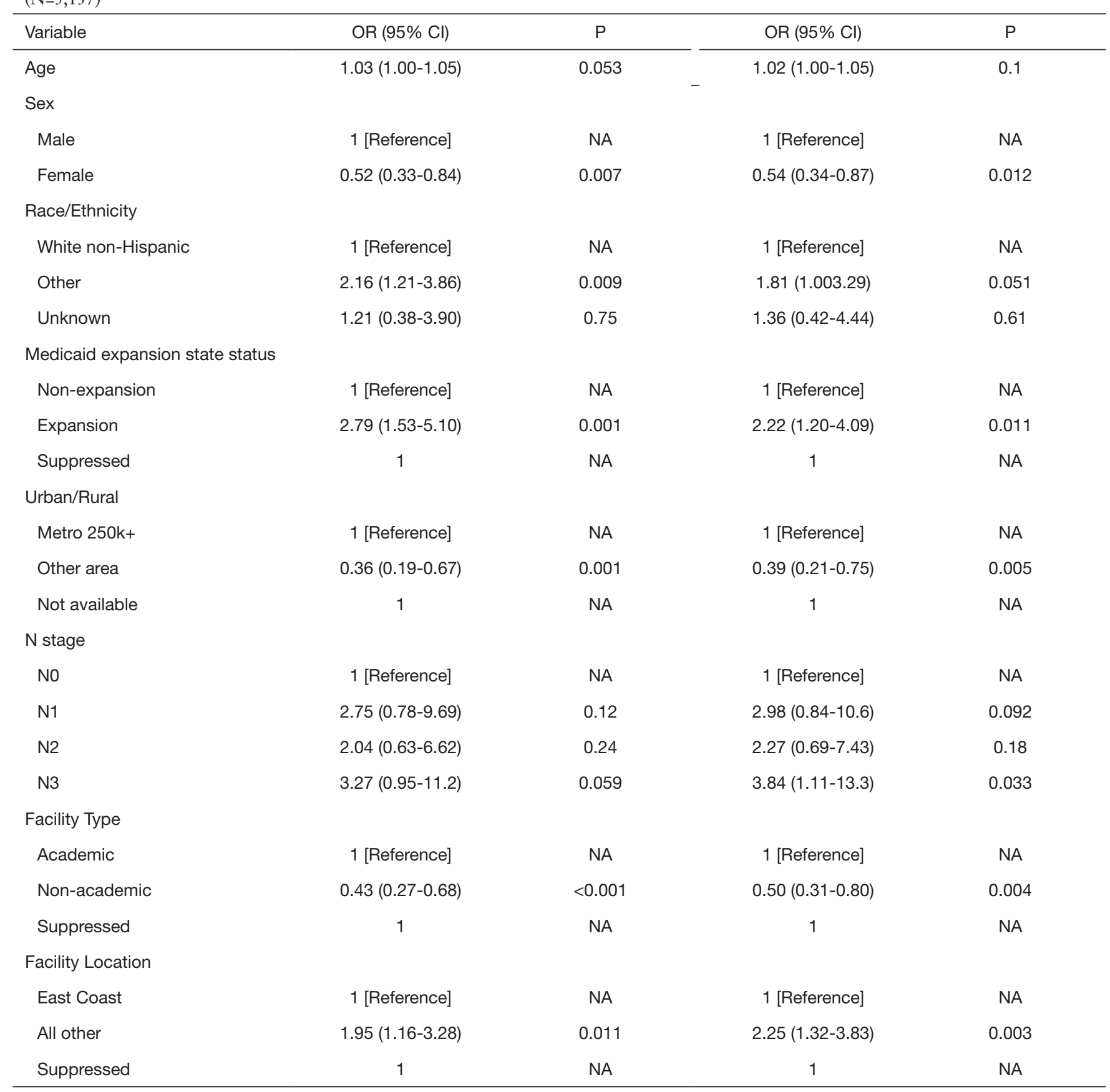

OR, odds ratio; $\mathrm{Cl}$, confidence interval. 
Table S4 Univariable and multivariable logistic regression analysis for variables potentially associated with receipt of hypofractionated radiation therapy (HFRT; N=79) compared to standard radiation therapy (standard RT; N=1,927) among the non-early concurrent chemotherapy subset $(\mathrm{N}=2,006)$

\begin{tabular}{|c|c|c|c|c|}
\hline \multirow{2}{*}{ Variable $^{\dagger}$} & \multicolumn{2}{|c|}{ Univariable } & \multicolumn{2}{|c|}{ Multivariable } \\
\hline & OR $(95 \% \mathrm{Cl})$ & $\mathrm{P}$ & OR $(95 \% \mathrm{Cl})$ & $\mathrm{P}$ \\
\hline \multicolumn{5}{|l|}{ Race/Ethnicity } \\
\hline White non-Hispanic & 1 [Reference] & NA & & \\
\hline Other & $0.99(0.52-1.90)$ & 0.98 & & \\
\hline Unknown & 1 & NA & & \\
\hline \multicolumn{5}{|c|}{ Medicaid expansion state status } \\
\hline Non-expansion & 1 [Reference] & NA & 1 [Reference] & NA \\
\hline Expansion & $2.67(1.55-4.60)$ & $<0.001$ & 2.07 (1.19-3.61) & 0.01 \\
\hline Suppressed & $4.81(0.58-39.7)$ & 0.15 & $1.53(0.18-12.8)$ & 0.69 \\
\hline \multicolumn{5}{|l|}{ Facility Type } \\
\hline Academic & 1 [Reference] & NA & 1 [Reference] & NA \\
\hline Non-academic & $0.13(0.08-0.22)$ & $<0.001$ & $0.14(0.08-0.24)$ & $<0.001$ \\
\hline Suppressed & $0.92(0.12-7.32)$ & 0.94 & 1 & NA \\
\hline
\end{tabular}

${ }^{\dagger}$, variables with empty spaces in multivariate column were not included in the final MVA model. OR, odds ratio; Cl, confidence interval. 